\title{
SYNTHESIS, CHARACTERIZATION AND SELECTIVITY OF MOLECULARLY IMPRINTED POLYMER (MIP) GLUCOSE USING POLYEUGENOL AS A FUNCTIONAL POLYMER
}

\author{
Muhammad C. Djunaidi ${ }^{1, *}$ and Yayuk Astuti ${ }^{1}$ \\ ${ }^{1}$ Department of Chemistry, Faculty Sciences and Mathematics, Diponegoro University \\ Central Java, Indonesia 50278 \\ "E-mail: choliddjunaidi@ live.undip.ac.id
}

\begin{abstract}
Research on the synthesis of Molecularly Imprinted Polymer Glucose was undertaken by using polyeugenol as a functional polymer and Polyethylene Glycol Diglycidyl Ether (PEGDE) as a crosslinker agent. Polieugenol generated from eugenol then was tied with glucose template and crosslinked with PEGDE (Polyethylene Diglicidil Glycol ether) with a mole ratio of 1:1. Analysis of the results of the polymerization and crosslinking was performed using IR, GPC, NMR and XRD. Optimization of the adsorbent was conducted by varying the template concentration, the particle size of the adsorbent and eluent type. Glucose was analyzed by 3,5 dinitrosalicylic acid method. The selectivity of the MIP adsorbent was compared to Non-Imprinting Polymer and tested against fructose molecule. A characterization of MIP Glucose consisted of a chemical resistance test, re-use and selectivity. It is expected that MIP glucose adsorbs glucose more than NIP either in glucose solution or glucose solution mixed with fructose. The result was MIP adsorbent adsorbed glucose more than NIP but did not adsorb fructose otherwise NIP. The results obtained shows that MIP Glucose was resistant to any kind of organic acids (acetic acid), inorganic acids $\left(\mathrm{HCl}, \mathrm{HNO}_{3}\right)$ and $\mathrm{NaOH}$. Reuse of MIP Glucose as the adsorbent shows slightly decreased ability to adsorbed glucose when using ethanol, but tended to be stable when using demineralized water as a released solvent. MIP Glucose selectivity was seen in HPLC analysis.
\end{abstract}

Keywords: MIP Glucose, Polyeugenol, Fructose, Selectivity

(C) RASĀYAN. All rights reserved

\section{INTRODUCTION}

Diabetes mellitus (DM) may lead to complications such as cardiovascular disease, kidney failure, blindness, impotence and gangrene. Most people (95\%) with diabetes are living with type II diabetes mellitus, a disease resulting from the inability of the pancreas to produce an adequate amount of insulin $^{1,2,3}$. Treatment of this disease is diet and glucose-lowering drugs in blood glucose levels. Glucose diet can be done in a way by providing sugar-free glucose for example by selectively adsorb glucose from the sugars sucrose (table sugar), leaving a fructose sugar. Fructose sugar is safe for people with diabetes. Molecular adsorption MIP (molecularly imprinted polymer) technology offered selective adsorption of glucose. Hydrogen bonding between amine groups of Poly(allylamine) (PAA) and the hydroxide group of glucose and the addition of a crosslinker enables to make effective mold cavity so that it is able to identify/adsorb glucose seven times the fructose, the compound with a structure very similar to glucose $e^{1,2,4,5,6}$. Eugenol, a product of our abundant natural material, with its three potential functional groups believed to be able to replace the function of a functional monomer PAA, was even able to increase the selectivity of MIP. Hydrogen bonds between the hydroxide groups in eugenol and its derivatives with the hydrogen atom of glucose compound were believed capable of making more effective the mold cavity and produced MIP adsorbent glucose safer.

\section{EXPERIMENTAL}

\section{Materials}

Methanol, ethanol and chloroform which were technical grade, demineralised water from Bratachem, Chemicals all quality Merck's pure analysis were PEGDE (polyethylene diglycidil Ether), $\mathrm{C}_{2} \mathrm{H}_{5} \mathrm{OC}_{2} \mathrm{H}_{5}$, Rasayan J. Chem., 12(2), 809-821(2019)

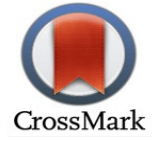


$\mathrm{BF}_{3} \mathrm{O}\left(\mathrm{C}_{2} \mathrm{H}_{5}\right)_{2}$, anhydrous $\mathrm{Na}_{2} \mathrm{SO}_{4}, \mathrm{NaOH}, \mathrm{HCl}, \mathrm{CH}_{3} \mathrm{OH}, \mathrm{K}-\mathrm{Na}$ tartrate, asam 3,5-dinitrosalisilat, D glucose, D fructose, acetic acid, and others were technic quality e.g.: ethanol, methanol.

\section{Instrumentation}

UV-Vis (Shimadzu type 1601), Infrared spectrometer (FTIR, Shimadzu Prestige-21), DTA/TGA (BÄHRThermoanalyse GmbH-simultaneous Thermal Analyser STA 503), HPLC (Shimadzu), XRD (Shimadzu XRD-8000).

\section{Procedure \\ Synthesis of Polyeugenol}

$5.8 \mathrm{~g}$ of eugenol was put into a 3-neck flask and was added with boron trifluoride diethyl etherate $\left(\mathrm{BF}_{3} \mathrm{O}\left(\mathrm{C}_{2} \mathrm{H}_{5}\right)_{2}\right)$ as much as $0.25 \mathrm{~mL}$ as a catalyst for the polymerization reaction. The catalyst was added 4 times every one hour while stirring with a magnetic stirrer. This reaction was allowed to occur at room temperature. The occurrence of the reaction was indicated by the change of the solution color from colorless to red. The reaction of polymerization was then allowed to take place continuously for 12-16 hours after the last addition of a catalyst. After which the addition of $1 \mathrm{~mL}$ of methanol into the flask was undertaken to stop the reaction. The resulting gel was dissolved in chloroform and transferred into a separating funnel. Furthermore, it was washed using distilled water for several times until neutral $\mathrm{pH}$ was obtained. The resulting organic layer was then moved into a $50 \mathrm{~mL}$ Erlenmeyer flask. Moreover, anhydrous $\mathrm{Na}_{2} \mathrm{SO}_{4}$ was added and followed by decantation. The solvent subsequently was evaporated at $40^{\circ} \mathrm{C}$ using a rotary evaporator. The dried residue was stored in a desiccator. The solid polymer produced was then weighed and characterized by FT-IR.

\section{Synthesis of MIP Glucose}

Grafting of glucose with polyeugenol. $0.5 \mathrm{~g}$ of polyeugenol was reacted with glucose with different concentration by stirring for $6 \mathrm{~h}$. The resulting product was then filtered using a filter paper and subsequently dried at room temperature.

Crosslinking polyeugenol-glucose with PEGDE as a crosslinker. $0.3 \mathrm{~g}$ of polyeugenol-glucose obtained from step A was crosslinked with PEGDE with a mole ratio of $1: 1$ by heating at of $80-90^{\circ} \mathrm{C}$ for 15 minutes using $20 \mathrm{ml}$ of $\mathrm{NaOH} 1 \mathrm{M}$ as a catalyst. The product was then neutralized by washing with distilled water and dried in an oven at $115^{\circ} \mathrm{C}$ for $6 \mathrm{~h}$. The final material produced in this method was the Polieugenol-glucose-PEGDE

Eluting glucose from Polyeugenol-glucose-PEGDE using an eluent. $0.2 \mathrm{~g}$ of Polyeugenol-glucosePEGDE synthesized in step B was eluted using an eluting solvent for $24 \mathrm{~h}$. Glucose had been eluted during this process and MIP glucose was produced.

\section{Synthesis of Non-Imprinting Polymer (NIP).}

NIP was synthesized using the same way of Glucose MIP synthesis, except there was no glucose grafting undertaken in the earliest stage.

\section{Characteristic of MIP Glucose Adsorbent}

Characterization of MIP glucose was done using FTIR, TGA/DTA, SEM and XRD.

\section{Adsorption of Glucose}

$50 \mathrm{mg}$ of MIP glucose was contacted with $3000 \mathrm{ppm}$ of glucose. The performance of glucose MIP was evaluated using different glucose concentrations, different solvents and particle sizes. Glucose was characterized by the UV-Vis spectrophotometer using 3,5 dinitrosalicylic acid as the complexing agent and analyzed with the UV spectrophotometer at $540 \mathrm{~nm}$.

\section{Making DNS Reagents}

$30 \mathrm{~mL}$ of distilled water was added with $0.5 \mathrm{~g}$ of $\mathrm{NaOH}$ and $9.1 \mathrm{~g}$ of $\mathrm{K}-\mathrm{Na}$ tartrate, stirring until dissolved. The mixture was then added to a solution of $0.5 \mathrm{~g}$ of the DNS (3,5-dinitrosalicylic acid) little 


\section{RASĀYAN J. Chem.}

Vol. 12 | No. 2 |809-821| April - June | 2019

by little while continuing stirring, then added $0.025 \mathrm{~g}$ of sodium sulfite and $0.1 \mathrm{~g}$ of phenol, and the mixture was stirred continuously until a homogeneous mixture was achieved. This reagent was then stored in a dark container.

\section{Determination of Glucose (and Other Reducing Sugars) Concentration with DNS Reagent}

The test tube was added $500 \mathrm{~mL}$ of glucose standard solution with certain concentration variations. Each standard solution was added $50 \mathrm{~mL}$ 3,5-dinitrosalicylic acid (DNSA) and $950 \mathrm{~mL}$ of distilled water. The solution then was stirred with a vortex for $1 \mathrm{~min}$ and heated 10 minutes at $100{ }^{\circ} \mathrm{C}$ and followed by cooling until it reached room temperature, then centrifuged for 3 minutes at a speed of $9,500 \times \mathrm{g}$ to obtain the supernatant brownish yellow. The supernatant from each glucose standard solution absorbance was measured using the UV-Vis spectrometer at $\lambda 540$.

\section{Determination of Glucose and Fructose Concentrations in Mixture Solution Using a HPLC Instrument \\ Preparation of Sample}

1. Sample aliquot was filtered with a millex $0.45 \mathrm{uM}$ and then diluted $50 \mathrm{x}$ by double-distilled water. The sample aliquot was then ready to inject to HPLC as many as $40 \mu \mathrm{L}$.

2. Preparation of Sugar (Glucose and Fructose in Mixture) Standard

3. Glucose and Fructose standards were prepared with a concentration of 500, 1000 and $1500 \mathrm{mgL}^{-1}$ in double-distilled water and take $40 \mu$ and Inject to HPLC

4. The HPLC instrument condition

Column: meta card $87^{\circ} \mathrm{C}$

Eluent: $\mathrm{H}_{2} \mathrm{O}$

Flow Velocity : $0.6 \mathrm{ml} / \mathrm{min}$

Temperature: $85^{\circ} \mathrm{C}$. Detector: RID.

\section{Reusable (DNS Analysis)}

$10 \mathrm{~mL}$ of glucose $300 \mathrm{ppm}$ was adsorbed by $0.05 \mathrm{~g}$ of MIP Glucose. Glucose adsorbed was leached from the adsorbent by ethanol and distilled water. This adsorption process was repeated for 10 times. Analysis of DNS reagent by UV-Vis was used to measure glucose which was not adsorbed.

\section{Chemical Resistance Test for MIP Adsorbent}

Chemical Resistance Test for MIP adsorbent was undertaken by immersing MIP adsorbent in a variation of solvents that were demineralized water, ethanol (10\%), methanol (10\%), acetic acid, and some inorganic solvents such as $\mathrm{HCl}, \mathrm{HNO}_{3}$ and $\mathrm{NaOH}$ with a concentration of $0.5 \mathrm{M}$ each. After immersing in a variation of solvents, the MIP adsorbent was analyzed using FTIR.

\section{Selectivity Test}

$300 \mathrm{ppm}$ of glucose and $300 \mathrm{ppm}$ of fructose were added in solution and adsorbed by MIP glucose and NIP and then analyzed by the HPLC instrument.

\section{Hydrolysis}

Hydrolysis of sugar was conducted by diluting a spoon of sugar in $250 \mathrm{~mL}$ distilled water and added a piece of lemon fruit and let them hydrolyzed into glucose and fructose for several days. The glucose and fructose concentrations as a result of hydrolysis were measured using the HPLC instrument. Sample aliquot was stored in a refrigerator until ready for being measured.

\section{Characterization of MIP Glucose}

\section{RESULTS AND DISCUSSION}

As we can see in Fig.-1, the role of -OH group in $3500-3600 \mathrm{~cm}^{-1}$ is very important. The polyeugenolglucose spectrum that indicates a spectrum of polyeugenol after adsorbing glucose compound showed an 
increase in $\mathrm{OH}$ - vibration mode ${ }^{7}$, but there is decreasing in the intensity of $\mathrm{OH}$ peak after crosslinking with PEGDE (polyeugenol-glucose-PEGDE). After releasing glucose by ethanol to form MIP Glucose (MIP Glu) there are slightly increasing of $\mathrm{OH}$ vibration modes indicating the presence of free $\mathrm{OH}$ groups increase. $\mathrm{OH}$ groups involved in the creating of MIP were reported by Djunaidi et al $(2015)^{7,8,9}$.

FTIR.

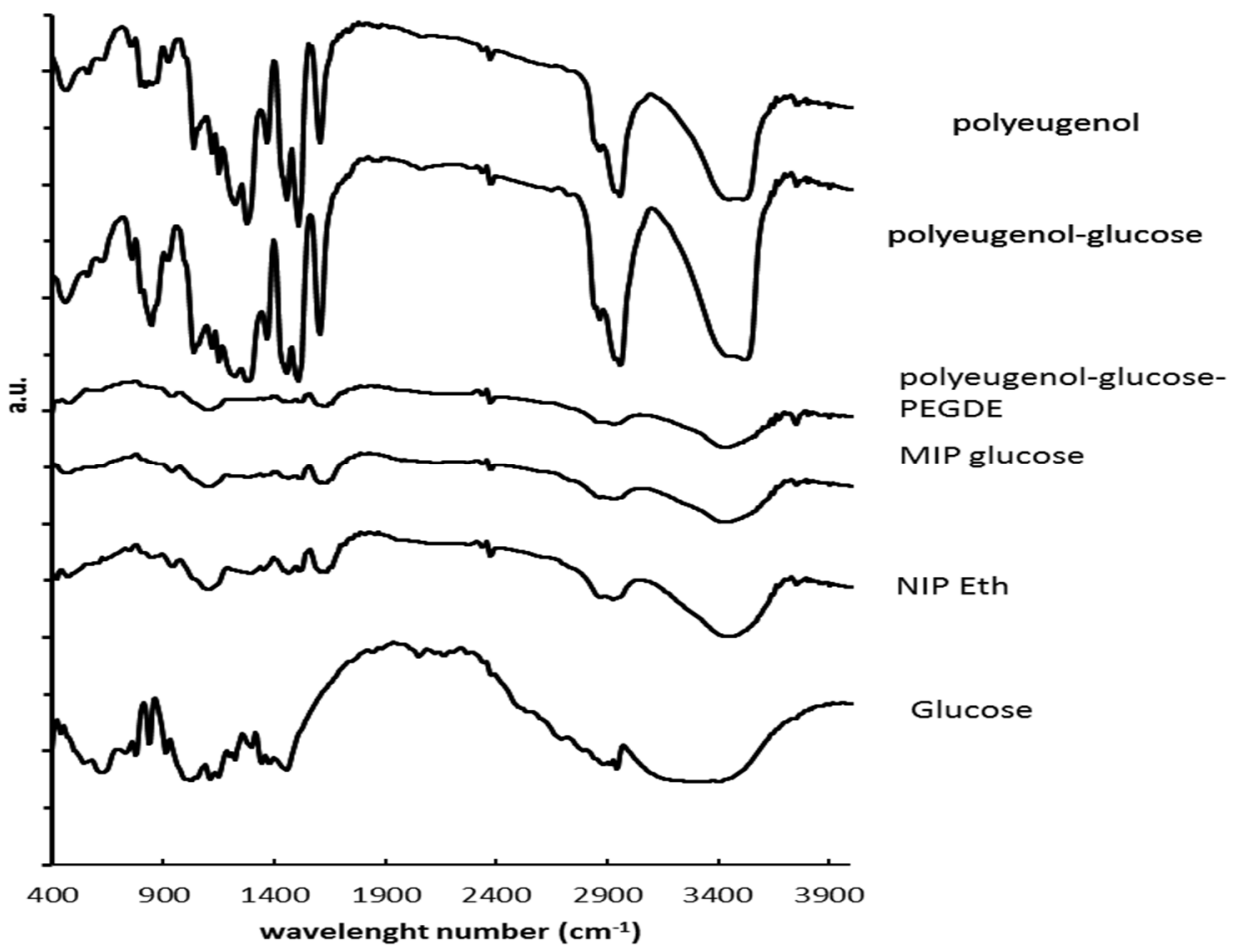

XRD

Fig.-1: FTIR Spectra of Various Adsorbents and Glucose.

Figure-2 shows X-ray diffractograms of various adsorbents indicating the bulkier polymer the smaller the crystallinity. MIP-Glu-PEGDE (MIP binding Glucose template and crosslinked by PEGDE) is the bulkier polymer ${ }^{10}$ otherwise polyeugenol is the most simple polymer so that it has opposite appearance after being analyzed using the XRD instrument.

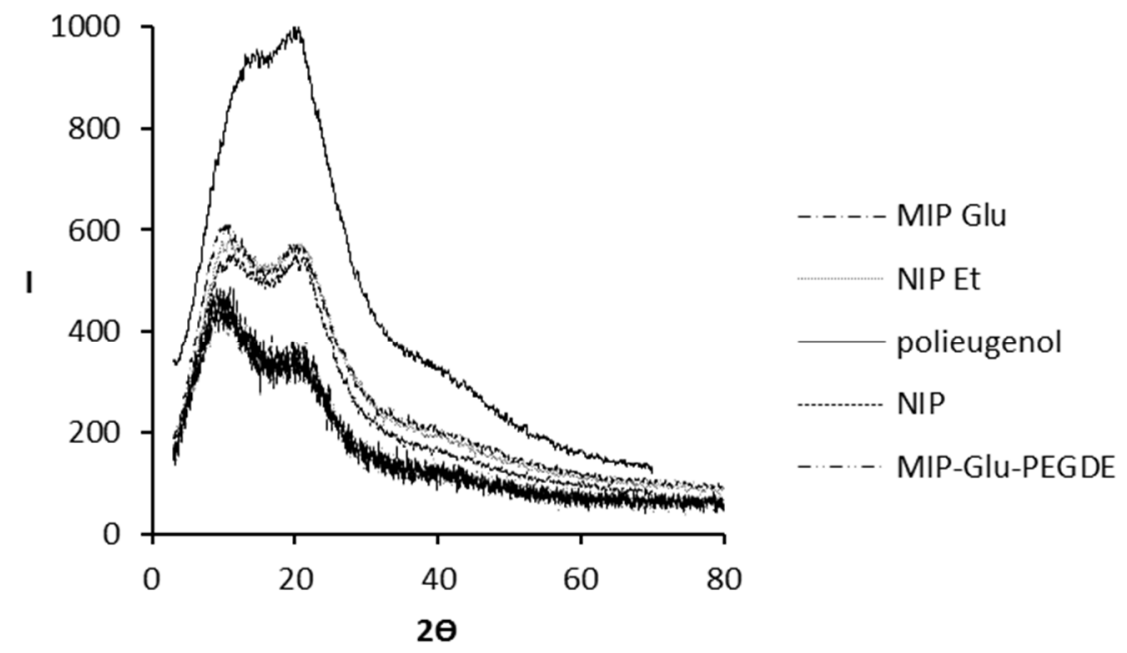

Fig.-2: X-Ray Diffractograms of Various Adsorbents. 
RASĀYAN J. Chem.

Vol. 12 | No. 2 |809-821| April - June | 2019

\section{TGA/DTA}

TheTGA / DTA curve of MIP Glucose (Fig.-3b) shows the sharp losses of weight at temperature of $400{ }^{\circ} \mathrm{C}$ which indicated an empty cavity in the adsorbent and free from Glucose. This did not occur in the NIP (Fig.-3a) and NIP Eth (Fig.-3c).

\section{SEM Analysis}
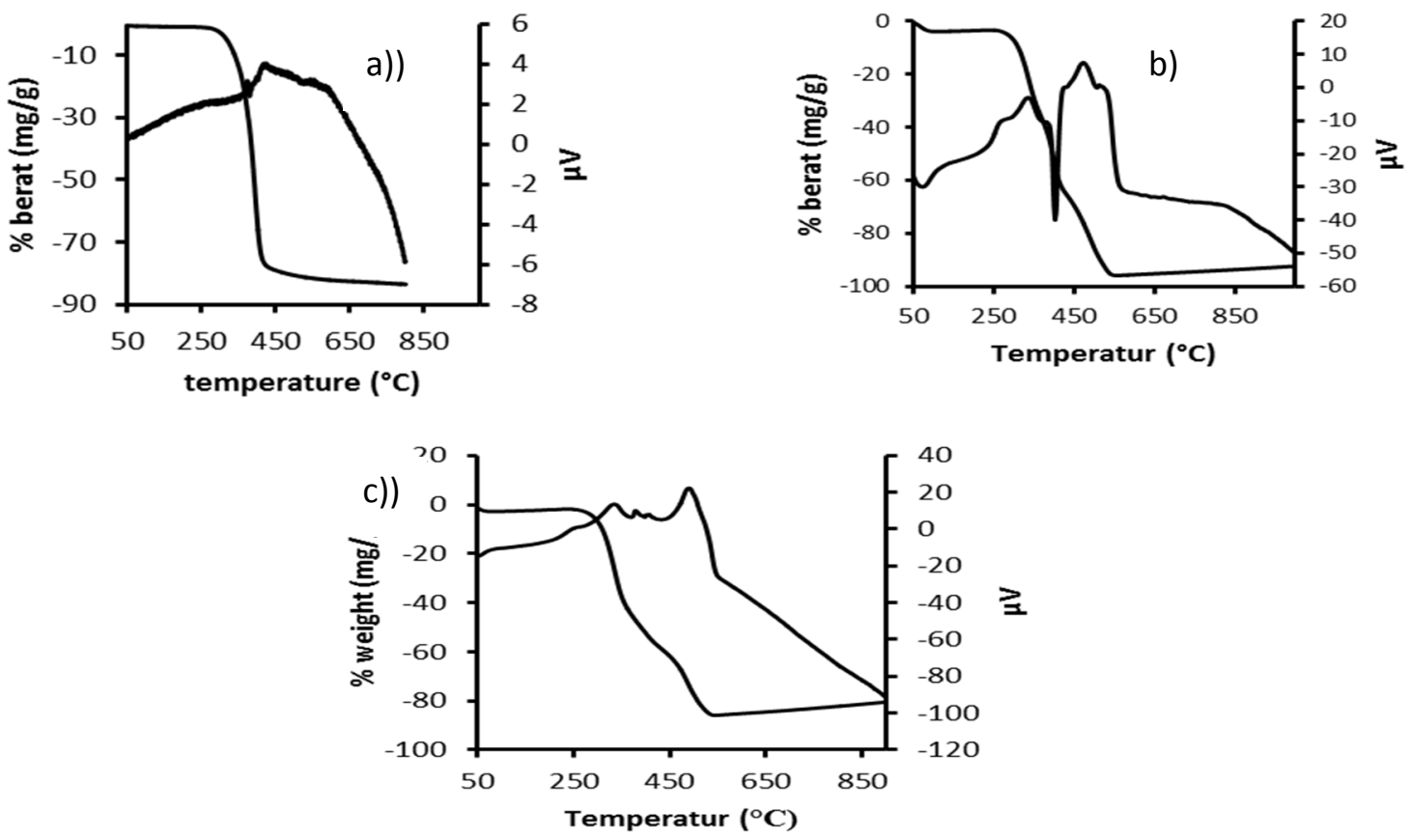

Fig.-3: TGA/DTA Curves of (a) NIP, (b) MIP Glucose, and (c) NIP Ethanol

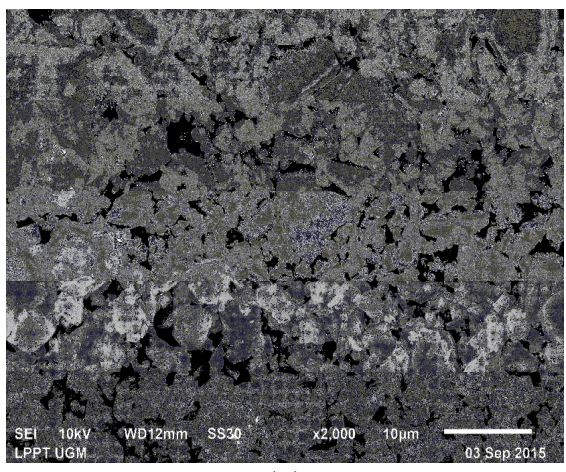

(a)

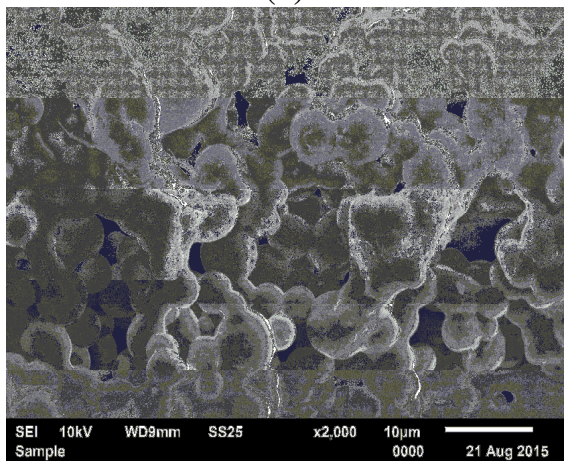

(c)

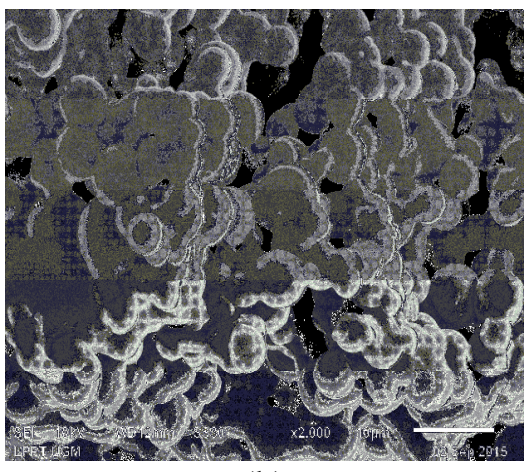

(b)

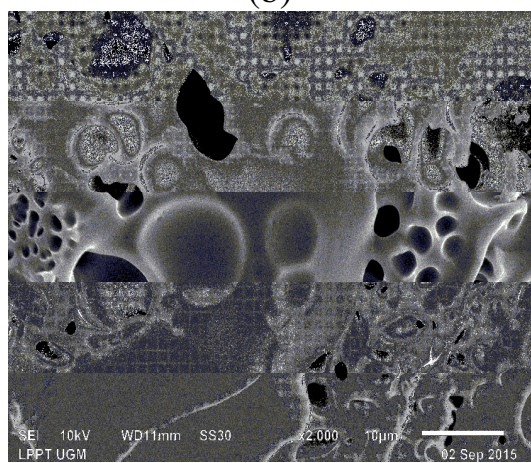

(d)

Fig.-4: SEM Images of (a) Polyeugenol, (b) NIP, (c) NIP Ethanol and (d) MIP Glucose 
As seen in Fig.-4, MIP Glucose (Fig. 4d) has relatively larger pores than the other adsorbents. This was as a result of the empty cavity created after the template was removed using ethanol solvent.

\section{Glucose analysis using DSN}

Analysis using DSN provides a standard curve by regression close to 1 as shown in Fig.-5. It indicates that this method was a good method for glucose analysis. Based on Fig.-5, statistically, the limit detection of glucose measurement using the DNS method is $0.072 \mathrm{mg} / \mathrm{L}$.

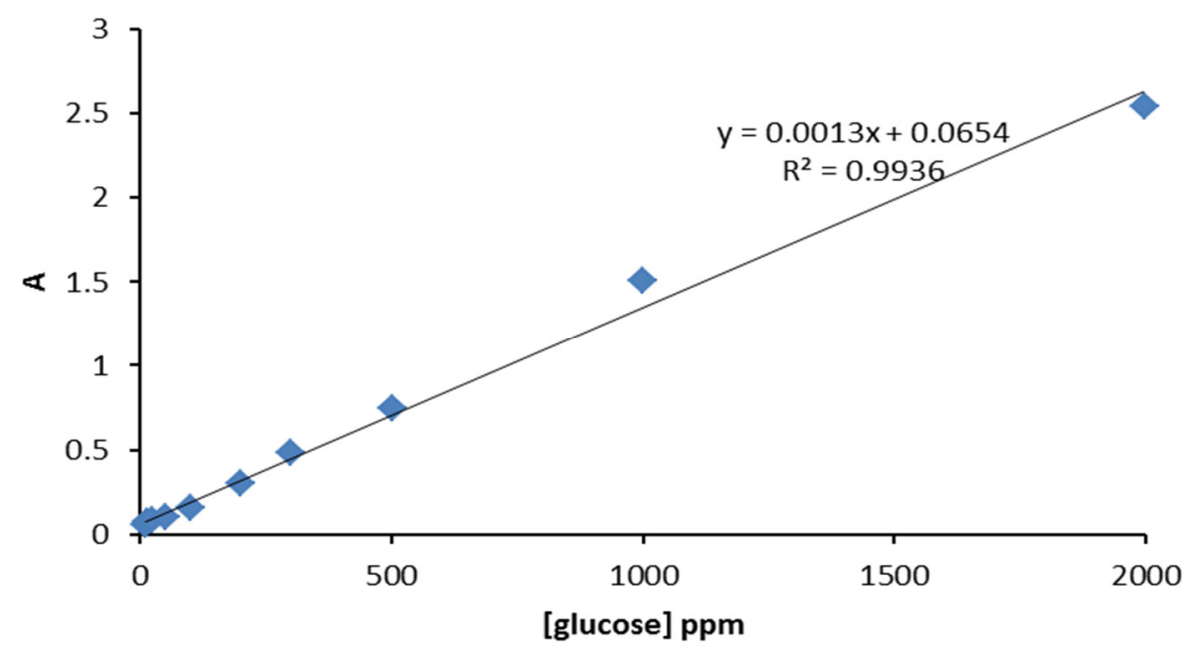

Fig.-5: Calibration Curve of Measurement Glucose in Various Concentrations Using Reagent DSN

\section{Glucose MIP Optimization}

Variations in the Concentration of the Template

The concentrations of glucose template were varied at 3000, 7500, 15000 and $10000 \mathrm{ppm}$.

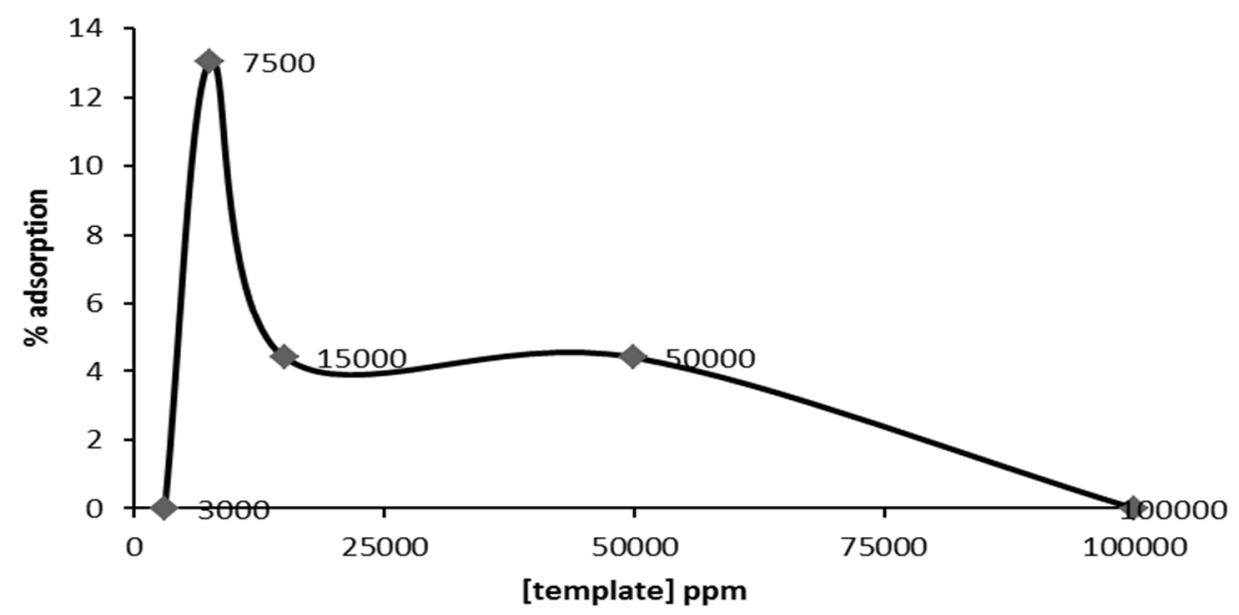

Fig.-6: The Curve of Various Concentrations of Glucose Template

Figure-6 shows that the saturated adsorption initially increased with increasing concentration of glucose template, this happened because the number of mold cavities (imprinted cavities) in the MIP increased if the amount of glucose increased, so the amount of saturated adsorption increased MIP ${ }^{8}$. Template of 3000 ppm glucose caused no \% glucose adsorption and resulted in NIP-like properties which did not adsorb glucose (Table-3).

After passing the glucose concentration of $7500 \mathrm{ppm}$ template, MIP adsorption amount decreased. This shows that at concentrations of $7500 \mathrm{ppm}$ glucose template, the maximum concentration of the mold 


\section{RASĀYAN J. Chem.}

Vol. 12 | No. 2 |809-821| April - June | 2019

cavity has been formed over the mold, so the number of mold cavities was reduced even though the concentration of glucose templates increased. Adsorption became fewer as much glucose "stuck" in the resin and could not be released by demineralized water. Furthermore, MIP with a template glucose concentration of $7500 \mathrm{ppm}$ was used for subsequent experiments.

\section{Variation of Eluent Templates}

To improve the performance of the MIP, varying the eluent templates was undertaken ${ }^{12}$. Types of eluents were water, ethanol and methanol. The results were analyzed on glucose adsorption with a concentration of 300 and 100 ppm. The results can be seen in Fig. -7.

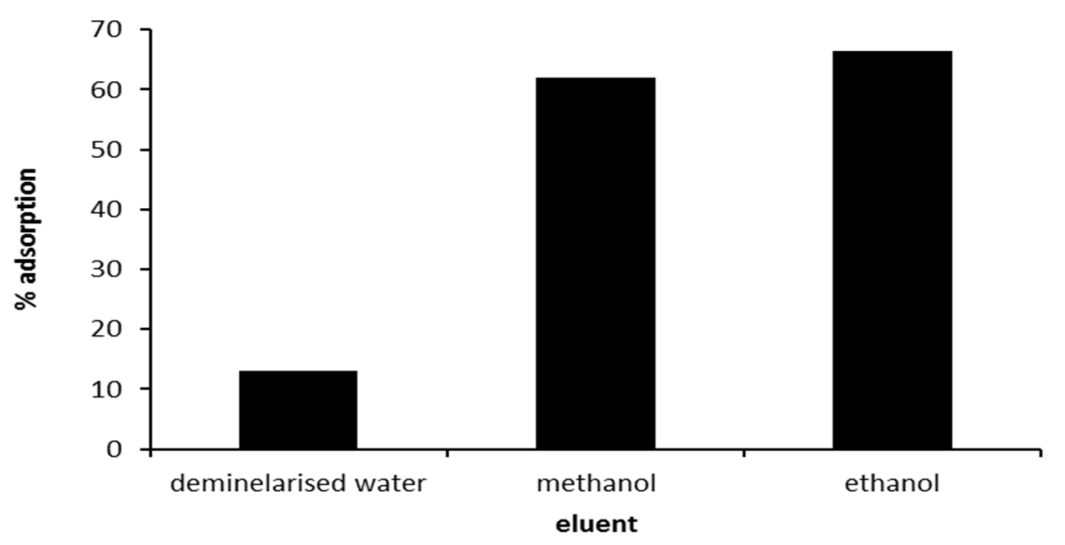

Fig.-7; Variation of Eluents for the Adsorption of 300 ppm Glucose

Figure-7 shows that ethanol eluent provided optimum percentage of adsorption, slightly better than methanol. A similar result was shown on the adsorption of 100 ppm glucose, as presented in Fig.-8.

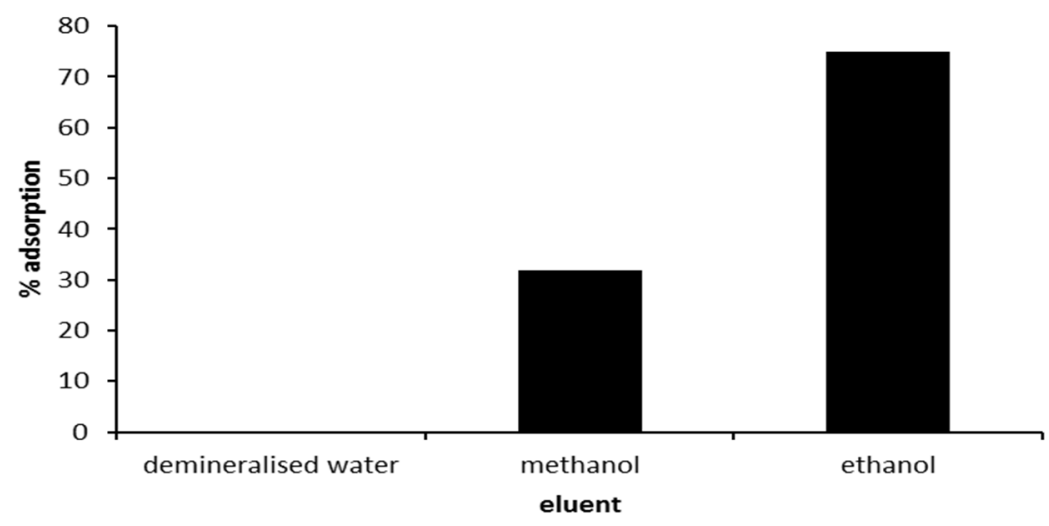

Fig.-8: Variation of the Eluents for the Adsorption of 100 ppm Glucose

Figure-8 shows the ethanol was much better than methanol in the elution of glucose. The eluent was used to washing off glucose to form MIP Glucose. These results were used for subsequent works.

\section{Particle Size Variation of MIP}

Figure-9 shows that the smaller the particle size the smaller the adsorption percentage. It likely occurred due to the damage of the imprinting glucose "space" when being ground into a smaller size.

\section{Adsorption Kinetics}

Adsorption kinetics was studied by modeling the data into pseudo-first-order kinetics equation (Lagergren) and pseudo-second-order kinetics equation (Ho). Pseudo-first-order kinetics equation is formulated as:

$\ln \left(q_{e}-q_{t}\right)=\ln \left(q_{e}\right)-k_{1} \mathrm{t}$ 
where, $\mathrm{q}_{\mathrm{e}}$ and $\mathrm{q}_{\mathrm{t}}$ are the sorption capacity at equilibrium and at time $\mathrm{t}\left(\mathrm{mmol} \mathrm{g}^{-1}\right)$ and $\mathrm{k}_{1}$ is a pseudo firstorder rate constant $1\left(\mathrm{~min}^{-1}\right)$.

Meanwhile, the equation of pseudo-second-order kinetic is formulated by:

$\frac{t}{q_{t}}=\frac{1}{k_{2} q_{e}^{2}}+\frac{1}{q_{e}} t$

where, $\mathrm{k}_{2}$ is a pseudo-second order constant $\left(\mathrm{g} \mathrm{mmol}^{-1} \mathrm{~min}^{-1}\right)$.

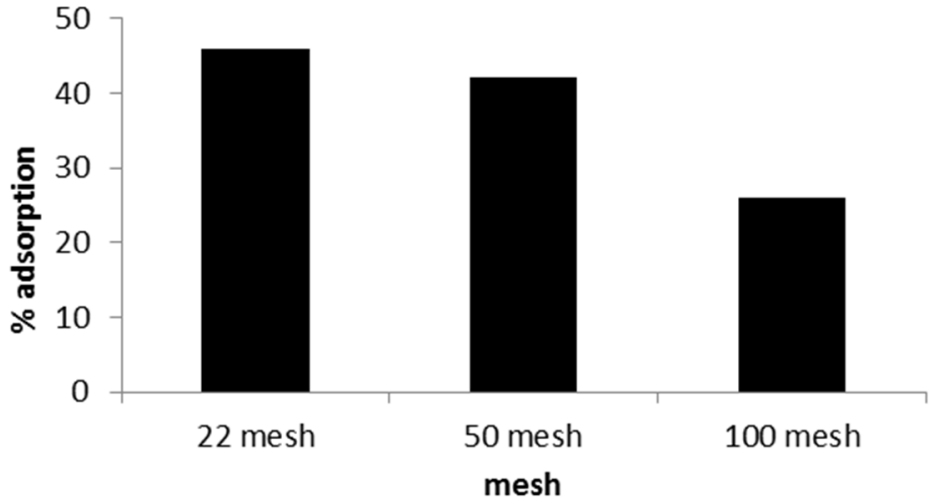

Fig.-9: Variation of the Particle Size of MIP for the Adsorption of 300 ppm Glucose

Table-1: Kinetic Parameters for Glucose Adsorption onto MIP

\begin{tabular}{|c|c|c|c|c|c|c|}
\hline \multirow{3}{*}{ Adsorbent } & \multicolumn{6}{|c|}{ Parameters } \\
\hline & \multicolumn{3}{|c|}{ Pseudo-order 1} & \multicolumn{3}{|c|}{ Pseudo-order 2} \\
\hline & $\begin{array}{c}\mathrm{q}_{\mathrm{e} 1} \\
\left(\mathrm{mg} \mathrm{g}^{-1}\right)\end{array}$ & $\begin{array}{c}\mathrm{k}_{1} \\
\left(\mathrm{~L} \mathrm{~min}^{-1}\right)\end{array}$ & $\mathrm{R}^{2}$ & $\begin{array}{c}\mathrm{q}_{\mathrm{e} 2} \\
\left(\mathrm{mg} \mathrm{g}^{-1}\right)\end{array}$ & $\begin{array}{c}\mathrm{k}_{2} \\
\left(\mathrm{~g} \mathrm{mg}^{-1} \min ^{-1}\right)\end{array}$ & $\mathrm{R}^{2}$ \\
\hline MIP Glucose & 0,68 & $-0,00028$ & 0,1903 & 47,619 & 0,000228 & 0,9822 \\
\hline
\end{tabular}

Parameters of pseudo-first order adsorption kinetics and pseudo second order for the sorption of Glucose onto MIP are shown in Table 1. Adsorption kinetics of Glucose onto MIP followed pseudo second order kinetics based on correlation coefficient value $\left(R^{2}\right) . R^{2}$ for pseudo second-order kinetics is higher than $R^{2}$ for pseudo-first order kinetics. Pseudo-second order kinetics required that the adsorption process is controlled by chemical bonding between adsorbent and adsorbate especially involving hydrogen bond between hydroxyl groups of glucose and atom hydrogen from polyeugenol or and PEGDE.

\section{Isoterm Adsorption}

Several models have been published to describe the adsorption isotherms. Freundlich and Langmuir adsorption isotherms are two types of models which are most often used as models of adsorption in solution.

Equation of Freundlich adsorption isotherm is an empirical equation used for adsorption on heterogeneous surfaces ${ }^{8}$. This equation is formulated as:

$$
\log m=\log K_{f}+\frac{1}{n} \log C_{\theta} \log m=\log K_{f}+\frac{1}{n} \log C_{\theta} \log \mathrm{m}=\log \mathrm{K}_{\mathrm{f}}+\frac{1}{\mathrm{n}} \log \mathrm{Ce}
$$

$\log \mathrm{m}=\log \mathrm{K}_{\mathrm{f}}+\frac{1}{\mathrm{n}} \log \mathrm{Ce}$

where, $\mathrm{m}$ is the number of metal ions adsorbed $\left(\mathrm{mmol} \mathrm{g}^{-1}\right), \mathrm{Kf}\left(\mathrm{L} \mathrm{mol}^{-1}\right)$ is the adsorption distribution coefficient related to Freundlich adsorption capacity, and $\mathrm{n}$ is the Freundlich constant indicating heterogeneity of the surface.

Langmuir adsorption isotherm equation is based on the assumption that the adsorption process occurs homogeneously and often applied for single layer adsorption. Langmuir equation is formulated as:

$\frac{\mathrm{C}_{e}}{\mathrm{q}_{\mathrm{e}}}=\frac{1}{\mathrm{bK}}+\frac{1}{\mathrm{~b}} \mathrm{C}_{\mathrm{e}} \frac{\mathrm{C}_{\mathrm{e}}}{\mathrm{q}_{\mathrm{e}}}=\frac{1}{\mathrm{bK}}+\frac{1}{\mathrm{~b}} \mathrm{C}_{\mathrm{e}} \frac{\mathrm{C}_{e}}{\mathrm{q}_{\mathrm{e}}}=\frac{1}{\mathrm{bK}}+\frac{1}{b} \mathrm{C}_{e}$ 
where, $\mathrm{q}_{\mathrm{e}}$ is the amount of adsorbate per unit weight of adsorbent at equilibrium $\left(\mathrm{mmol} \mathrm{g}^{-1}\right), \mathrm{C}_{\mathrm{e}}$ is the adsorbate concentration in the aqueous phase at equilibrium $\left(\mathrm{mmol} \mathrm{L}^{-1}\right), \mathrm{b}$ is the Langmuir adsorption capacity $\left(\mathrm{mmol} \mathrm{g}^{-1}\right), \mathrm{K}\left(\mathrm{L} \mathrm{mol}^{-1}\right)$ is the Langmuir adsorption equilibrium constant that can be used to determine the adsorption energy.

Table-2: Langmuir and Freundlich Isotherm Constants for Glucose Adsorption at the Solution pH Value of 3 and $25^{\circ} \mathrm{C}$

\begin{tabular}{|c|c|c|c|c|c|c|c|c|}
\hline \multirow[t]{3}{*}{ Adsorbent } & \multicolumn{5}{|c|}{ Langmuir Isotherm Parameters } & \multicolumn{3}{|c|}{$\begin{array}{c}\text { Freundlich Isotherm } \\
\text { Parameters }\end{array}$} \\
\hline & \multirow{2}{*}{$\begin{array}{c}\mathrm{b}\left(\mathrm{mgg}^{-}\right. \\
1)\end{array}$} & \multicolumn{2}{|c|}{$\mathrm{K}$} & \multirow[t]{2}{*}{$\mathrm{R}^{2}$} & \multirow{2}{*}{ 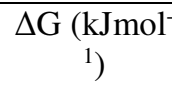 } & \multirow{2}{*}{$\begin{array}{c}\mathrm{KF} \\
\left(\mathrm{mgg}^{-1}\right)\end{array}$} & \multirow[t]{2}{*}{$\mathrm{n}$} & \multirow[t]{2}{*}{$\mathrm{R}^{2}$} \\
\hline & & $\left(\mathrm{Lmg}^{-1}\right)$ & $\left(\mathrm{Lmol}^{-1}\right) \times 10^{4}$ & & & & & \\
\hline MIP Glu Et & 38.332 & 0.000298 & 0.000373 & 0.996 & -42.380 & 1.2358 & 1.903 & 0.9754 \\
\hline
\end{tabular}

Table-2 shows the parameters of Freundlich and Langmuir isotherm adsorptions. Adsorption of Glucose on MIP was in agreement with the Langmuir isotherm adsorption with $\mathrm{R}^{2}=0.9996$. The adsorption capacity of Glucose on MIP was $38.332 \mathrm{mgg}^{-1}$. The adsorption capacity of $38.332 \mathrm{mgg}^{-1}$ is in the range of other researchers ${ }^{1,2,4,11}$.

The thermodynamic parameter for the adsorption process such as free energy $\left(\Delta G^{0}\right)$ can be calculated from Langmuir equilibrium constant using equation ${ }^{8,9}, \Delta \mathrm{G}^{0}=-\mathrm{RT} \ln \mathrm{K}^{7}$ in which $\mathrm{R}$ is the general gas constant $\left(8.314 \mathrm{~J} \mathrm{~K}^{-1}\right.$ mole $\left.^{-1}\right), \mathrm{T}(\mathrm{K})$ is the temperature. Free energies of physisorption, of the physisorption together with chemisorption and of chemisorption itself are respectively lower than $-20 \mathrm{~kJ}$ $\mathrm{mol}^{-1}$, at the range of -20 to $-80 \mathrm{~kJ} \mathrm{~mol}^{-1}$ and at a range of -80 to $-400 \mathrm{~kJ} \mathrm{~mol}^{-19}$. In Table- $2, \Delta \mathrm{G}^{0}$ value for adsorption of Glucose on MIP was $-42.38 \mathrm{~kJ} \mathrm{~mol}^{-1}$; thus this adsorption involved physisorption and chemisorption simultaneously.

\section{Adsorption Selectivity}

The adsorption selectivity was determined by adding $50 \mathrm{mg}$ of adsorbents (MIP and NIP Et in the different chambers) to $10 \mathrm{~mL}$ of a solution containing 200, 300 and $500 \mathrm{ppm}$ glucose. The adsorption was conducted in a batch system equipped with a magnetic stirrer. The result can be seen in Fig.-10.

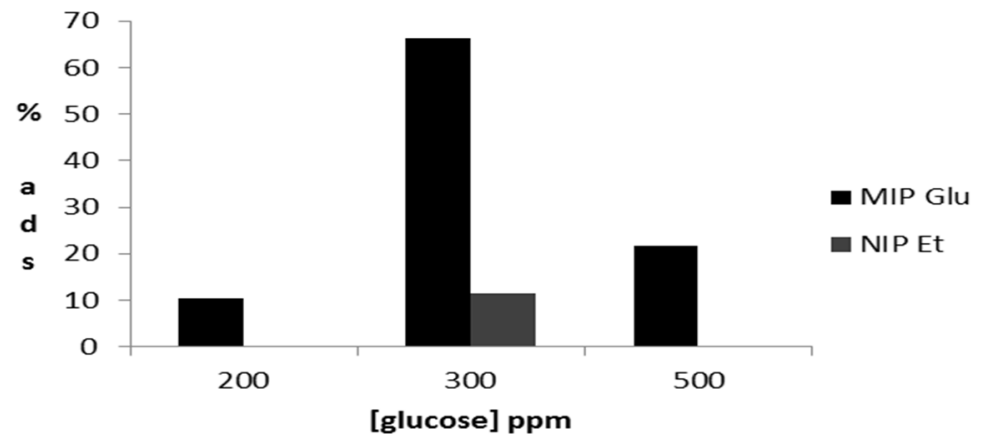

Fig.-10: Adsorption Percentage of MIP compared to NIP Et

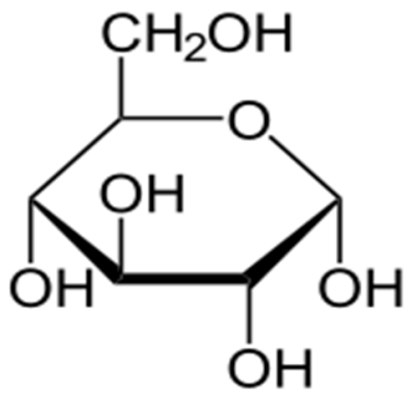<smiles>O=CC(O)C(O)C(O)C(O)CO</smiles>

Fig.-11: Molecular Structure of Glucose 
Figure-10 shows that MIP Glucose adsorbed glucose more than NIP, selective pores for Glucose in MIP contributed to this phenomenon. The selectivity of MIP towards glucose (structure of glucose as seen in Fig.-11) was proved because $300 \mathrm{ppm}$ fructose was not adsorbed (Table-3) (structure of fructose as seen in Fig.-12), a compound that has a very similar structure with glucose.
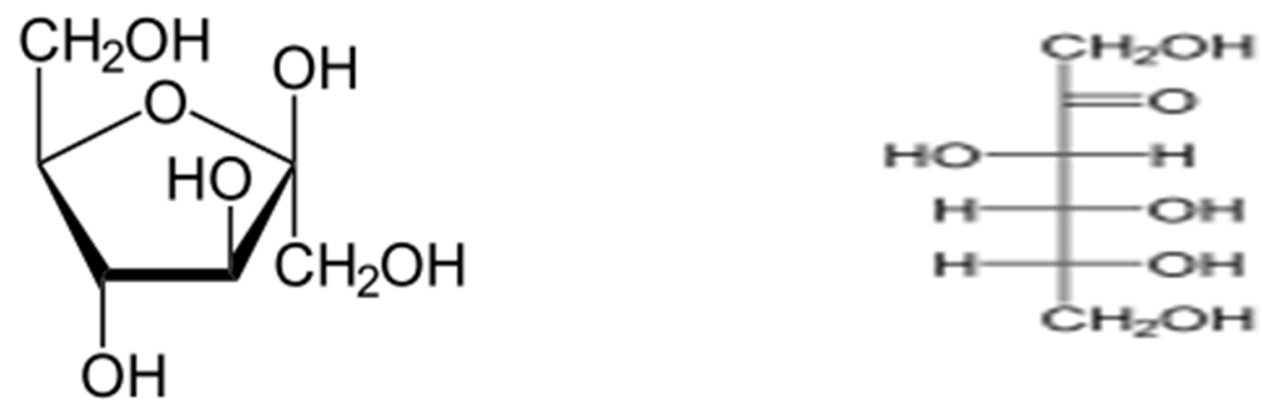

Fig.-12: Molecular Structure of Fructose

Table-3 shows that MIP did not adsorb fructose, otherwise NIP adsorbed fructose. NIP just adsorbed a little amount of glucose, contrary with MIP.

\section{Chemical Resistance Test of MIP Glucose}

Chemical Resistance Test for MIP adsorbent was conducted by immersing MIP adsorbent into a variation of solvents both inorganic acids and organic solvents. The adsorbent MIP after immersed by solvents was tested by FTIR.

\section{Inorganic Acids}

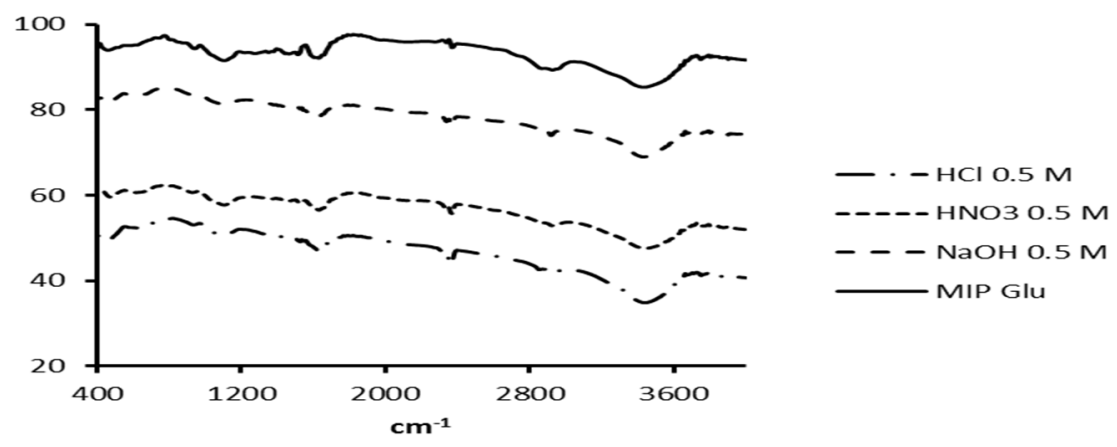

\section{Organic Acids}

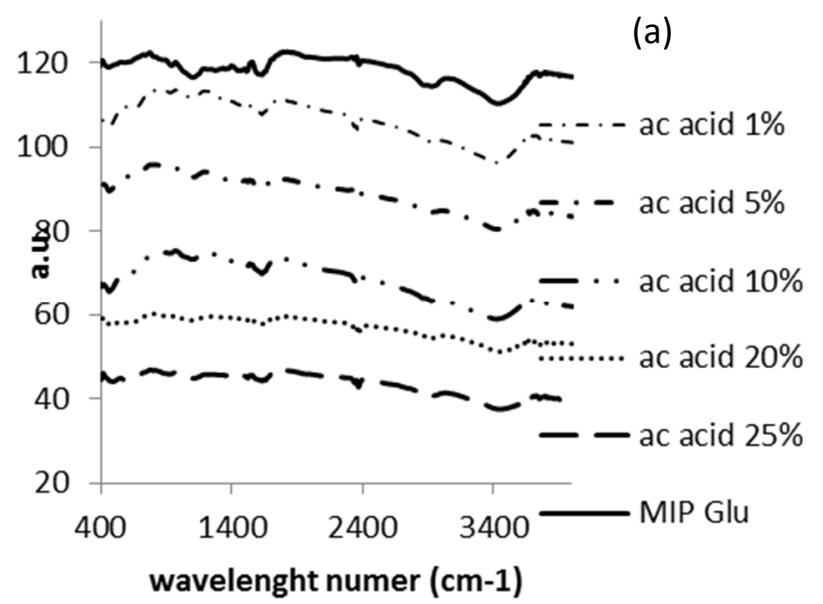

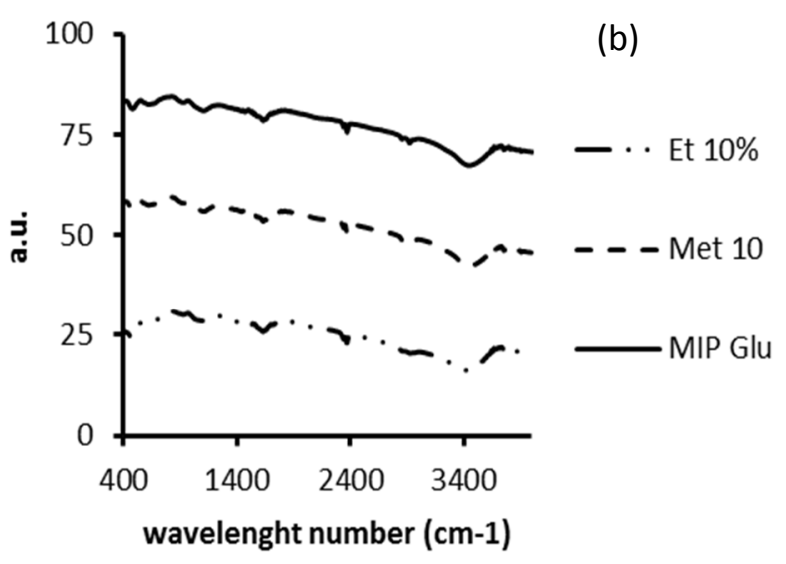

Fig.-14: FTIR Spectra of MIP Glucose after immersing in (a) Acetic Acid (b) Ethanol (10\%) and Methanol (10\%) 
RASĀYAN J. Chem.

Vol. 12 | No. 2 |809-821| April - June | 2019

Table-3: The Selectivity of MIP on Glucose and Fructose Adsorption compared to NIP

\begin{tabular}{ccc}
\hline Materials & \multicolumn{3}{c}{$\%$ Adsorption } \\
\cline { 2 - 3 } & Glucose $300 \mathrm{ppm}$ & Fructose $300 \mathrm{ppm}$ \\
\hline MIP Glucose & 66 & 0 \\
NIP Et & 11,58 & 11,58 \\
\hline
\end{tabular}

As seen in Fig.-13 and Fig.-14, there is no any new spectra appeared when compared to MIP Glucose, this indicates good resistance to various inorganic as well as organic solvents. Especially for the acetic acid solvent, MIP showed the chemical resistance below $20 \%$; above $20 \%$ there was a slight decomposition of Glucose MIP. This can be seen from the decline in the intensity of the IR absorption.

\section{Reusable of MIP Glucose}

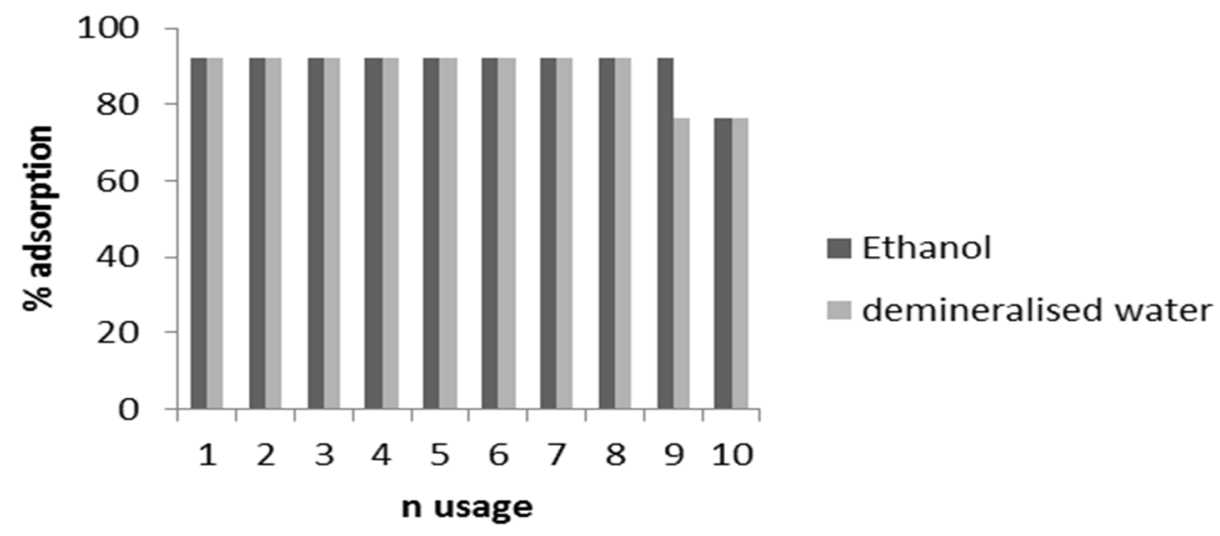

Fig.-15: Reusable of MIP Glucose

As seen in Fig.-15, the use of both desorption solvents (demineralized water and ethanol) showed a good reusable until eight $\left(8^{\text {th }}\right)$ usage, $9^{\text {th }}$ and $10^{\text {th }}$ indicating reduction of MIP ability to adsorb glucose although not too large.

\section{Selectivity in Mixture Solution of Glucose and Fructose}

The selectivity of MIP in the solution can be undertaken by comparing adsorption percentage of MIP towards glucose compared to fructose. The results can be seen in Table-4. As shown in Table-4, MIP selectivity was good because of adsorbed more glucose than fructose and sucrose. Fructose has a similar chemical structure with glucose and only being distinguished by its functional groups.

\section{Hydrolysis}

Fructose can be generated from the hydrolysis of sucrose / table sugars with lemon as a catalyst. An experiment was carried out to know the result of a comparison between hydrolysis with and without the catalyst lemon. The results can be seen in Table-5.

Table-4: Adsorption Percentage of MIP and NIP towards Fructose and Glucose in Simulation Mixture Solution.

\begin{tabular}{|c|c|c|c|c|c|c|}
\hline & \multicolumn{2}{|c|}{ Fructose } & \multicolumn{2}{|c|}{ Glucose } & \multirow{2}{*}{$\begin{array}{c}\text { Sucrose } \\
\begin{array}{c}\text { Adsorption } \\
\text { by MIP }\end{array}\end{array}$} & \multirow{2}{*}{$\begin{array}{c}\text { Ratio } \\
\text { (Fructose/Glucose) } \\
\text { Rest }\end{array}$} \\
\hline & ppm & $\begin{array}{l}\text { \% Adsorption } \\
\text { by MIP }\end{array}$ & ppm & $\begin{array}{c}\text { \% Adsorption } \\
\text { by MIP }\end{array}$ & & \\
\hline Start & 316.54 & & 286.5 & & & 1.1 \\
\hline NIP $0.1 \mathrm{~g}$ & 312.47 & 1.29 & 271.2 & 5.34 & 0 & 1.15 \\
\hline NIP $0.05 \mathrm{~g}$ & 301.72 & 3.39 & 255.25 & 10.91 & 0 & 1.18 \\
\hline MIP $0.1 \mathrm{~g}$ & 294.84 & 6.86 & 131.31 & 54.17 & 0 & 2.25 \\
\hline MIP $0.05 \mathrm{~g}$ & 304.65 & 3.76 & 150.87 & 47.34 & 0 & 2.02 \\
\hline
\end{tabular}

It can be seen in Table-5 that when the lemon catalyst was not used the hydrolysis of sucrose into glucose and fructose did not occur. On the other hand, when lemon was used, on the third $\left(3^{\text {rd }}\right)$ day to $10^{\text {th }}$ 
hydrolysis processes produced fructose and glucose with the ratio in the range of 1:22 to 1:59, the role of acid is very important in this case ${ }^{13}$.

\begin{tabular}{|c|c|c|c|c|c|c|}
\hline \multirow[t]{2}{*}{ Catalyst } & \multirow[t]{2}{*}{ Repetition } & \multicolumn{2}{|c|}{ ppm } & \multicolumn{2}{|c|}{$\%$} & \multirow{2}{*}{$\begin{array}{c}\text { Ratio } \\
\text { Fructose/Glucose }\end{array}$} \\
\hline & & Glucose & Fructose & Glucose & Fructose & \\
\hline \multirow{2}{*}{$\begin{array}{l}\text { Demineralised } \\
\text { water }\end{array}$} & 1 & - & - & - & - & \\
\hline & 2 & - & - & - & - & \\
\hline \multirow[t]{2}{*}{ Lemon (3 ds) } & 1 & 547. & 664.25 & 1.47 & 1.66 & 1.22 \\
\hline & 2 & 631.66 & 661.51 & & & \\
\hline \multirow[t]{2}{*}{ Lemon (10 ds) } & 1 & 446.13 & 706.49 & 2.23 & 3.56 & 1.59 \\
\hline & 2 & 447.48 & 715.6 & & & \\
\hline
\end{tabular}

The adsorption on the aliquot result of hydrolysis on day $3^{\text {rd }}$ using MIP adsorbent led to increasing of the ratio of fructose/glucose. This occurred since the MIP did not adsorb fructose but only adsorbed glucose. It can be seen in the comparison between the ratio of remaining fructose/glucose after MIP adsorption in simulation and hydrolysis solutions that were 2.02 and 1.78, respectively (see Table-6). The lower ratio of remaining fructose/glucose in hydrolysis solution is due to the complexity of this solution.

Table-6: Adsorption of Glucose as a Result of Sugar Hydrolysis

\begin{tabular}{c|c|c}
\hline & Initial Ratio & Ratio After Adsorption by MIP \\
\hline Lemon (3 ds) & 1.22 & 1.78 \\
\hline
\end{tabular}

\section{CONCLUSION}

1. In this work, MIP Glucose was prepared using glucose as an imprinted molecule, polyeugenol as a polymer and PEGDE as a cross-linker.

2. MIP also showed good resistance to organic solvents and inorganic acids.

3. MIP showed good selectivity towards glucose compared to NIP, and did not adsorb fructose, even in a mixture of simulation solution as well as in the result of hydrolysis.

4. MIP Glucose in this research results is still in the range of previous studies so that they are still potential to develop more.

\section{ACKNOWLEDGMENT}

The authors thank The Ministry of Research and Technology and Higher Education of the Republic of Indonesia for research funding.

\section{REFERENCES}

1. P. Parmpi, P. Kofinas, Biomaterials, 25(10), 1969 (2003), DOI: 10.1016/j.biomaterials.2003.08.025

2. P. Paraskev, L. D. V. Bolisay, and P. Kofinas, MRS Online Proceedings Library Archive, 787, G6.2.1 (2003), DOI: 10.1557/PROC-787-G6.2

3. H. Darmokoesoemo, L. Kustyarini, M. Khasanah, and H. S. Kusuma, Rasayan Journal of Chemistry, 10(1), 64 (2017), DOI: 10.7324/RJC.2017.1011559

4. W. J. Wizeman, and P. Kofinas, Biomaterials., 22(12), 1485 (2001), DOI: 10.1016/S01429612(00)00303-3

5. F. Fazal, and D. E. Hansen, Bioorganic \& Medicinal Chemistry Letters, 17(1), 235 (2006), DOI: 10.1016/j.bmcl.2006.09.054

6. M. Ibrahim, M. Alaam, H. El-Haes, A. F. Jalbout, A. de Leon, Ecletica Quimica, 31(3), 15 (2006), DOI: $10.1590 /$ S0100-46702006000300002

7. M.C. Djunaidi, R. A. Lusiana, P. J. Wibowa, D. Siswanta, Jumina, Alchemy Journal Penelitian Kimia, 6, 40 (2007)

8. M.C. Djunaidi, Jumina, D. Siswanta, M. Ulbricht, Indonesian Journal of Chemistry, 15(3), ( 2015), DOI: $10.22146 /$ ijc. 21200

9. M.C. Djunaidi, Jumina, D. Siswanta, M. Ulbricht, Asian Asian Journal of Chemistry, 27(12), 4553 (2015), DOI: $10.14233 /$ ajchem.2015.19228 


\section{RASĀYAN J. Chem.}

Vol. 12 | No. 2 |809-821| April - June | 2019

10. Yanti , T. Nurhayati, I. Royani, Widayani, Khairurrijal, Journal of Physics: Conference Series, 739(1), 012143 (2016), DOI: 10.1088/1742-6596/739/1/012143/

11. A.L. Baliro, R.A. Santos, M.M. Pereira, R.T. Figueiredo, L.S. Freitaws, O.L.S. de Alsina, A.S. Lima, C.M.F. Soares, Brazilian Journal of Chemical Engineering, 33(02), 361 (2016), DOI: 10.1590/01046632.20160332s20140089

12. B. Okutucu, S. Onal, Talanta, 87, 74 (2011), DOI: 10.1016/j.talanta.2011.09.043.

13. D. Irawan, Z. Arifin, Rasayan Journal of Chemistry, 10(4), 1302 (2017), DOI: 10.7324/RJC.2017.1041945

[RJC-5120/2018] 